\title{
Understanding trust on social networking sites among tertiary students: An empirical study in Ghana
}

Felix Nti Koranteng

Department of Information Systems and Innovation,

Ghana Institute of Management and Public Administration, Achimota-Accra, Ghana

Isaac Wiafe and Ferdinand Apietu Katsriku

Department of Computer Science, University of Ghana, Legon-Accra, Ghana, and

Richard Apau

Department of Computer Science,

Kwame Nkrumah University of Science and Technology (KNUST), Kumasi, Ghana

Trust on social networking sites

\begin{abstract}
User trust in social networking sites (SNS) has become an important issue in SNS discussions. This is because of its impact on knowledge sharing, social commerce, social interaction, among many others. However, information systems researchers have primarily explored the benefits of trust with little attention to its antecedents. In an attempt to address this knowledge gap, this study proposed a model that investigated the factors that promote trust among SNS users. Data was gathered from voluntary respondents using a questionnaire. A PLS-SEM analysis of 912 valid responses suggested that Norm of Reciprocity, Social Interaction Ties and Identification are significant factors that encourage Trust among SNS users. Shared Language was also identified to have impact on Norm of Reciprocity, Social Interaction Ties and Identification. The results of the study provide significant theoretical and practical contributions. They bridge the knowledge gap regarding the formation of Trust on SNS. The model evaluated explains $49.6 \%$ of the variance in Trust and thus suitable for analyzing the antecedents of Trust on SNS. Furthermore, with the significance of Identification, Social Interaction Ties and Norm of Reciprocity on Trust, SNS developers are tasked to offer SNS features that proliferate the formation of these factors as well as shared interpretations.
\end{abstract}

Keywords Social networking sites, Trust, Social Network Trust, Shared language, Social capital Paper type Original Article

(C) Felix Nti Koranteng, Isaac Wiafe, Ferdinand Apietu Katsriku and Richard Apau. Published in Applied Computing and Informatics. Published by Emerald Publishing Limited. This article is published under the Creative Commons Attribution (CC BY 4.0) license. Anyone may reproduce, distribute, translate and create derivative works of this article (for both commercial and non-commercial purposes), subject to full attribution to the original publication and authors. The full terms of this license may be seen at http:// creativecommons.org/licences/by/4.0/legalcode.

Declaration of Competing Interest: None.

Publishers note: The publisher wishes to inform readers that the article "Understanding trust on social networking sites among tertiary students: An empirical study in Ghana" was originally published by the previous publisher of Applied Computing and Informatics and the pagination of this article has been subsequently changed. There has been no change to the content of the article. This change was necessary for the journal to transition from the previous publisher to the new one. The publisher sincerely apologises for any inconvenience caused. To access and cite this article, please use Nti Koranteng, F., Apietu Katsriku, F., Apau, R., "Understanding trust on social networking sites among tertiary students: An empirical study in Ghana", Applied Computing and Informatics. Vol. ahead-of-print No. ahead-of-print. https://10.1016/j.aci.2019.07.003. The original publication date for this paper was 31/07/2019.
Received 14 March 2019

Revised 24 July 2019

Accepted 30 July 2019 


\section{Introduction}

The rapid evolution of the Internet over the last decades has transformed the world into a global village. Recent technologies such as social networking sites (SNS) have provided the necessary infrastructure and platform to support the development of new social structures [51]. Currently, social networking sites enable effective ways for knowledge sharing, collaboration and professional networking [24,52]. Due to the popularity of these innovations among students, higher educational institutions are increasingly adopting it to improve students' experience [20]. College students have particularly, been identified as the most dominant user group of SNS [38]. They frequently interact, collaborate and share knowledge using these media [2,75]. This makes SNS an innovative alternative in enhancing students' engagement and learning outcomes [38,72]. Nonetheless, they have also created new challenges for peer-to-peer communication [40]. Specifically, interactions on these platforms are mostly technology-mediated and thus limit interpersonal relationships based on face-toface communication. Consequently, the absence of face-to-face interaction affects the level of trust among users [23].

Trust is one's belief in the capabilities, honesty and reliability of others [34]. It is a peer's confidence that others will not knowingly cause harm to them [14]. Similar to face-to-face interaction, trust is a major factor that affect online behavior [13]. Chiu et al. [14] indicated that trust is actually one of the main barriers of online communication. Other studies have also demonstrated the importance of trust in related activities such as online knowledge sharing behavior among tertiary students [47]. Trust has the ability to reduce uncertainties and associated risk [50]. Despite the extant literature on online trust, many of these studies sought to investigate the consequences of trust rather than its antecedents [40]. Thus, studies that examine the factors that enable the formation of trust on social networking sites are inadequate [68].

Given that college students prefer interactions on SNS than offline environments [70], contributions to theories that promote trust on SNS platforms will impact its usage. More importantly, as higher educational institutions continue to adopt SNS to engage students in learning activities (and the increasing prominence of trust) it has become imperative to understand the factors that informs trust among students on these platforms. In doing so, institutions will be better equipped in facilitating teaching and learning activities. This paper therefore seeks to expand the current literature on SNS and Trust. It adopts concepts from the social capital theory to investigate the factors that promote the formation of trust among users of SNS in higher education. The next section discusses related literature on SNS and Trust. This is followed by a review of the fundamental theory for the study. Furthermore, the data analysis, results and discussions are also presented. This paper ends with drawn up theoretical and practical contributions. Finally, conclusions and suggestions for future studies are drawn.

\section{Literature review}

Trust has been studied among scholars from diverse disciplines. This has resulted in varied definitions for the concept [46]. Sociologists define trust as a set of expectations held by individuals involved in an exchange[93]. From a social learning perspective, it is the expectations shared by individuals that a promise or word of other individuals could be relied upon [73]. It can also be regarded as a psychological state comprising the intention to accept vulnerability based upon positive expectations of the behavior of another [10]. In a nutshell, trust may be bottled up as the willingness of a person to be defenseless to others based on the assumption that they will conform to expected behavior irrespective of the ability to monitor or control the other party [76]. Researchers have defined trust in the context of person to person relations as applied in traditional offline environment. Nonetheless, these definitions 
may be applicable in online environments since the social principles of interaction in both offline and online settings are similar [87]. Thus, studies have successfully adopted and applied these definitions in online trust studies [3,14,53,52]. Following a similar approach, this study defines trust as the believe that network members will not knowingly cause harm to others and will adhere to the acceptable norms [52].

Although offline trust definitions are applicable in online settings, the situational elements that influence the formation of trust differs. For instance, exchange appears to be a common factor in both settings [7], however, exchanges in offline environments are different from online settings. Issues regarding physical distance is also different in these environments. One of the benefits of online communities is increased access to informational resources [39]. In offline environments, students for example are limited to forming groups with a few colleagues within a specific geographic boundary. This means that students are limited and hugely dependent on their circle. Meanwhile, SNS eliminate these geographical boundaries. They provide a vast array of competitive alternatives as well as new information sources [1]. They also increase students' sovereignty and this affects the nature of trust formation within SNS [64]. In addition, human network attributes such as non-verbal language on which trust is built in the traditional environment are absent on SNS. Thus it reduces the richness of communication among members [31]. These differences emphasize the need to investigate trust on SNS.

Yet, prior studies have mostly explored online trust as a consequence often within the context of e-commerce $[28,65,80]$, e-government $[60,74,86]$ and knowledge sharing $[14,53,52]$ with fewer studies on antecedents of trust among online social network members. Hsu et al., [46] explored the antecedents of trust among members of a virtual community. The researchers observed that knowledge growth, perceived responsiveness and shared values affect trust positively. Benefit attraction and shared values have also been found to impact trust significantly [90]. According to Wang [87], trust among SNS members is influenced by information quality, reciprocity, shared value, reputation, satisfaction and SNS interaction with familiarity as a moderating construct.

Gefen, Benbasat, \& Pavlou [36] identified how differences in culture affects trust and therefore call for researchers to explore the concept across different geographic domains. In other words, the factors that promote interpersonal trust in society differ. This is because, the formation of trust is informed by individual's beliefs and values which are often guided by culture. As such, individuals from cultures that are threatened by uncertainties are less trusting than the others [78]. Hence, there is the need to test if the confirmed relationships in previous studies hold in countries with higher uncertainty avoidance. In addition, the study will also uncover the factors that promote trust with samples from higher uncertainty avoidance countries.

\subsection{Theoretical framework}

A number of theoretical models have been developed to explain trust formation. In Moorman, Deshpande, \& Zaltman [61]'s framework, trust building is considered to consist of three stages: antecedents, process and outcomes. The antecedents refer to the determinants of trust. According to Moorman et al., [61], trust is mainly determined by individual characteristics (e.g. job experience) and organizational characteristics (e.g. organizational structure). Relatedly, McKnight, Choudhury, \& Kacmar [58] also proposed the Trust Building Model (TBM). The model explains that reputation, information quality, organizational factors and perceived risks informs trust. Similarly, other studies have adopted the CommitmentTrust Theory (CTT) [62] to explain the antecedents of trust. In the CTT, trust is dependent on shared values, communication and opportunistic behavior. Although these models have been widely used in virtual community trust research [87], their applicability are mainly focused on 
person-to-organization or person-to-technology [57]. This study, however, focuses on the relationships between users of SNS and influential factors for the formation of trust. Therefore, the aforementioned theories are less applicable.

The Social Capital Theory (SCT) suggests that resources are gained through social relationships [69]. It argues that individuals derive benefits from associating with others [17]. It is a multidimensional construct represented as having structural, relational and cognitive dimensions. The structural dimensions describe the form of relationships, pattern of linkages and how connections among individuals are configured [8]. Its relational dimension deals with the nature of the connections among network members. The major resources of this dimension are trust, norms of reciprocity and identification. The cognitive dimension deals with similarities in members' beliefs and understanding. The major features of this dimension are shared language and codes. Following Chang and Chuang [12] and Koranteng \& Wiafe [52], this study adopts Social Interaction Ties as a variable of the structural dimension; Trust, Identification and Norm of Reciprocity as variables for the relational dimension and finally Shared Language as a manifestation of the cognitive dimension. This approach reduces measurement errors and enables the researchers to compare the validity of similar variables across different contexts.

In recent times, the SCT has become popular in discussing issues relating to relationships among users on online networks. This is because, online social networks possess features that facilitate the accumulation of benefits such as employment, reputation, information, power, influence, etc. [27]. Accordingly, researchers have adopted the theory to explain information exchange, knowledge sharing and civic engagement, [3,14,53,52,85,88], mostly as a derived benefit. SCT is suitable for investigating issues regarding social relationships hence consistent with the objective of this study. Hämäläinen [43] argues that there is a positive relationship between the social capital constructs. In other words, trust can be measured as a product of other constructs [87]. Hence, this study investigates the interrelationships between Social Interaction Ties, Identification, Norm of Reciprocity and Shared Language and their influence on Trust. Table 1 summarizes the construct definitions and literature sources whereas Figure 1 presents the hypothesized model.

\subsection{Hypothesis formulation}

2.2.1 Shared Language, Norm of Reciprocity, social Interaction Ties and Identification. Shared language refers to a common vocabulary that permits a shared understanding among group members [3] and creates a pedestal for people to significantly interact and return actions [66]. It supports effective communication and verbal exchanges Furthermore, shared language facilitates the development of common behavioral principles and homogenous symbol systems that enhances affiliation and attachment towards group members [33]. Sin \& Kim

Table 1.

Definition of Constructs and Sources.

\begin{tabular}{lll}
\hline Construct & Definition & Source \\
\hline Shared Language (SL) & $\begin{array}{l}\text { It is a common vocabulary that enable network members to communicate } \\
\text { with a common understanding. }\end{array}$ & {$[3,29,53]$} \\
$\begin{array}{lll}\text { Norm of Reciprocity } \\
\text { INR) }\end{array}$ & $\begin{array}{l}\text { It is the tendency of people to feel compelled to return actions when they } \\
\text { believe others will do same for them. }\end{array}$ & {$[3,14]$} \\
$\begin{array}{l}\text { Social Interaction Ties } \\
\text { (SIT) }\end{array}$ & $\begin{array}{l}\text { It represents the frequency of interactions and the strength of the } \\
\text { relationship among network members. }\end{array}$ & {$[14,52]$} \\
Identification (ID) & $\begin{array}{l}\text { It refers to an individual's perception of inclusiveness in a community. } \\
\text { Trust (TR) }\end{array}$ & $\begin{array}{l}\text { It is the believe that network members will not knowingly cause harm to } \\
\text { others and adhere to the acceptable norms. }\end{array}$ \\
& & {$[52]$}
\end{tabular}




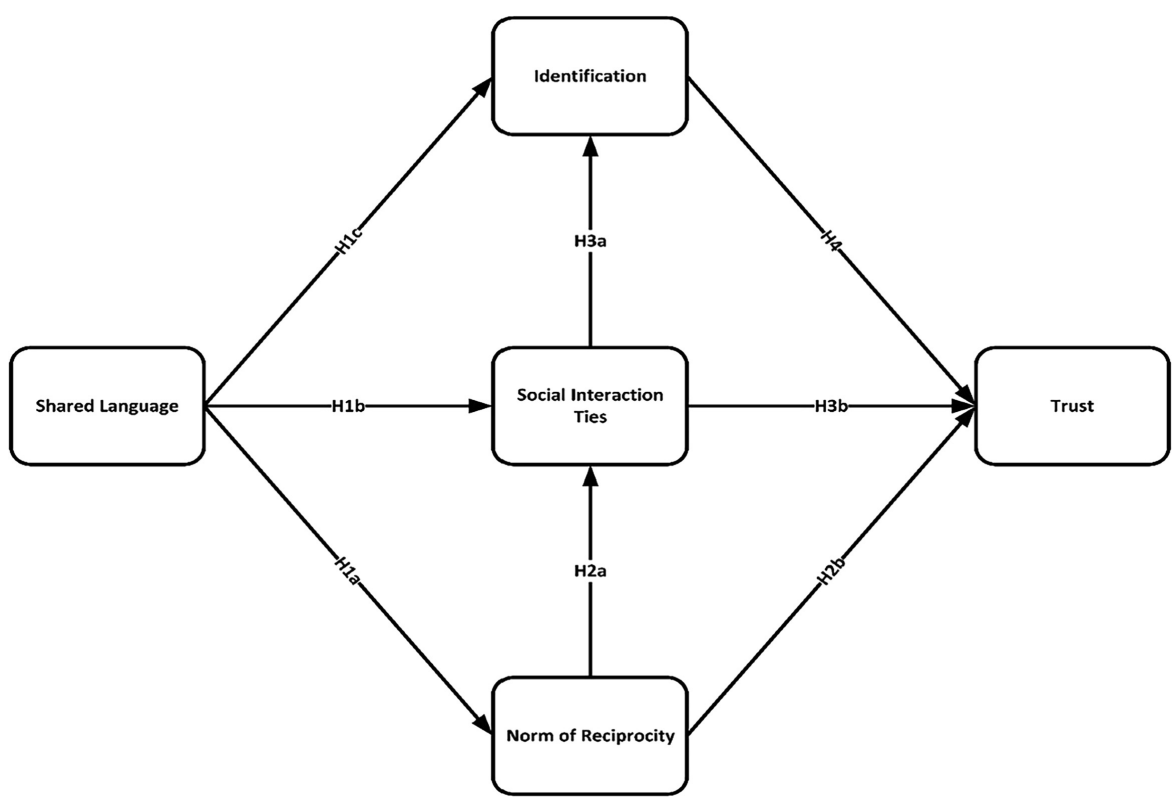

Trust on social networking sites

Figure 1.

Proposed Research Model.

[79] identified language as a major barrier for successful interaction among networked members. Undeniably, it is easier for people to build stronger bonds and reciprocate kindness when they share common attributes [87]. Empirical evidence from Koranteng et al., [53] indicates that shared language is a pre-requisite for knowledge exchange. Thus, shared language encourages member involvement in group discussions Aslam et al. [3] which provoke stronger ties and a sense of belonging [33]. The formation of shared interpretation on SNS seems to be problematic because it connects users from different geographical location and cultural disciplines. However, SNS link individuals with common beliefs and norms, and provide an enabling environment for common understanding [77]. Therefore, it is hypothesized that;

$\mathrm{H}_{1 \mathrm{a}}$ : Shared Language positively affect Norm of Reciprocity on social networking sites

$\mathrm{H}_{1 \mathrm{~b}}$ : Shared Language positively affect Social Interaction Ties on social networking sites

$\mathrm{H}_{1 \mathrm{c}}$ : Shared Language positively affect Identification on social networking sites

2.2.2 Norm of reciprocity, social interaction ties and trust. Norm of Reciprocity is defined by members perception that interactions among themselves is mutual and fair [14]. It is the expectation that other group members will return favors. The principles of the Social Exchange Theory propose that there is higher resource exchange when group members observe a strong norm of reciprocity [21]. Similarly, mutual and fair exchanges build strong ties among members which promotes trust [87]. That is, members' responsiveness increases the intensity of communication among themselves and thus their integrity and benevolence [71]. Also, people are more likely to trust others who reciprocate support and help [30]. Though it is widely accepted that SNS facilitate information exchange [54], scholars have indicated that reciprocity is nonexistent on these platforms. For example, Collins et al. [18] and Meishar-Tal \& Pieterse [59] assert that SNS users are consumers of information but do not actively engage in creation and sharing. To test this claim, we hypothesized that: 
$\mathrm{H}_{2 \mathrm{a}}$ : Norm of Reciprocity positively affect Social Interaction Ties on social networking sites.

$\mathrm{H}_{2 \mathrm{~b}}$ : Norm of Reciprocity positively affect Trust on social networking sites.

2.2.3 Social Interaction Ties, Identification and trust. Social Interaction Ties denotes the intensity of interactions between group members [14]. It outlines the strength of relationship and communication frequency among members [84]. Higher interaction among members leads to higher self-identification and trust among members [71]. Consequently, the more people are familiar with members within their network, the more they feel attached and trust them [84]. Social networking sites eliminate communication barriers such as distance and cost [22] by providing users with effective tools for synchronous communication. Lim \& Richardson [54] opine that, social networking sites augment frequent information exchange. Therefore promoting closeness among network members will lead to an enhanced sense of belonging and trust Dubos [25]. According to Koranteng et al., [53], frequent communication is a precursor of trust. Similarly, Mu, Peng, \& Love [63] confirm that, close interactions among network members increases their inclusiveness and positive feeling towards each other. However, in contrast, Tonioni et al., [83] argue that social networking sites use reduces social involvement and make users lonely and depressed. To validate the above claims, the following hypotheses were tested:

$\mathrm{H}_{3 \mathrm{a}}$ : Social Interaction Ties positively affect Identification on social networking sites.

$\mathrm{H}_{3 \mathrm{~b}}$ : Social Interaction Ties positively affect Trust on social networking sites.

2.2.4 Identification and trust. As defined earlier, Identification embodies a person's perceptions of his/her inclusiveness in a societyChiu et al. [14]. It measures an individual's positive feeling and sense of attachment within a community. The development of such attachments has been argued to be doubtful on social networking sites given concerns such as cyber-bullying [35]. Conversely, findings from Malatesh \& Dhanasree [55] refute such claims. Social networking sites connect like-minded users to exchange affective and emotional support [48]. This facilitates the development of mutual commitment, attachment and loyalty [49] and therefore trust among network members [82]. According to the social identity theory [81] people perceive their network members in more desirable ways (i.e. trustworthy) than others outside the network. Similarly, Dumitru and Schoop [26] found a significant relationship between Identification and Trust among group members. Hence it is hypothesized that;

$\mathrm{H}_{4}$ : Identification positively influence Trust on social networking sites.

\section{Research methodology}

A quantitative survey approach was adopted for this study. Google Form was used to design an English-based questionnaire which was distributed via social networking platforms such as Facebook, WhatsApp, Twitter, etc. This approach ensured that all participants are familiar with online social networks. The approach was also meant to explore responses from a variety of SNS users unlike Wang [87] who sampled only users of Wei Bo (an SNS platform in China). Although participation was solely voluntary, the questionnaire was also designed to ensure anonymity and confidentiality. A brief statement that explained the purpose of study was attached to the questionnaire. Relevant respondents' demographics and their perceptions on key variables that promote trust were collected. Thus, the five-point Likert scale questions ranging from "strongly agree" (5) to "strongly disagree" (1) were used to measure respondent's perception relating to (i) Shared Language (ii) Social Interaction Ties 
(iii) Identification (iv) Norm of Reciprocity and (v) Trust were measured. All constructs and question items were adopted and modified from prior studies (see Table 1). Respondents were recruited using convenience sampling technique.

\subsection{Data collection}

Convenience sampling was used to select 2000 respondents from 3 main public universities in Ghana and questionnaire was sent to them via various SNS platforms. This sampling approach was used because none of the universities agreed to provide a full list of enrolled students, thus a true random sampling could not be performed. Nine hundred and twenty-one (921) responses were received, indicating a response rate of $46 \%$. All respondents were active SNS users who spent at least $30 \mathrm{~min}$ a day on SNS platforms. Since all fields in the questionnaire were mandatory, there was no missing data in the 921 responses received. Out of this sample, $72 \%$ were male and the rest (28\%) were female. Majority representing $48 \%$ were below 30 years whereas $39 \%$ were between 30 and 40 and $13 \%$ above 40 . Most of the responses came from undergraduate students $(69 \%)$ and $31 \%$ were postgraduate students. A summary of the respondents' demographics is shown in Table 2.

\section{Analysis and findings}

The hypothesized model was validated using Partial Least Square Structural Equation Modelling (PLS-SEM). This technique was adopted not only because of its suitability for exploratory studies [41] and predicting the relationships between latent variables [42] but also its robustness to errors from multivariate distributions [37]. Furthermore, since the sample size is larger than ten times the number of structural paths directed at a construct, PLS-SEM is considered suitable for this study. The SmartPLS 3.0 was used to analyze the structural model.

\subsection{Measurement}

In Structural Equation Modelling (SEM), Coltman et al. [19] argued that analysis of the measurement model must focus on item reliability, internal consistency, convergent validity and discriminant validity. Therefore, this approach was adopted for analyzing the measurement model. All item loadings (see appendix) were above Barclay et al. [6]'s recommended threshold of 0.7 hence they were considered valid. Internal consistency was measured using Cronbach's Alpha and composite reliability. Table 3 indicates that all constructs were above 0.7 as suggested by Bagozzi and Yi [4]. The Average Variance

\begin{tabular}{|c|c|c|c|c|}
\hline Demographics & Value & Frequency & Percentage & \\
\hline \multicolumn{5}{|l|}{ Sex } \\
\hline & Male & 663 & $72 \%$ & \\
\hline & Female & 258 & $28 \%$ & \\
\hline \multicolumn{5}{|l|}{ Age } \\
\hline & Below 30 & 442 & $48 \%$ & \\
\hline & $30-40$ & 359 & $39 \%$ & \\
\hline & Above 40 & 120 & $13 \%$ & \\
\hline \multirow[t]{3}{*}{ Highest Education Level } & & & & Table 2. \\
\hline & Postgraduate & 635 & $69 \%$ & Demographics of \\
\hline & Uniter grauduate & & & \\
\hline
\end{tabular}


Extracted (AVE) was used to test the convergent validity. All AVEs greater than 0.5 are considered to be valid [89]. Discriminant validity was evaluated with both the Fornell-Lacker criterion [32] and Heterotrait-Monotrait Ratio (HTMT) [45]. Using the Fornell-Lacker criterion, discriminant validity was tested by finding the square root of the AVEs of the latent variable and compared to the correlations between the corresponding latent variable and other latent variables. Fornell \& Lacker [32] recommended that the square root of the AVE of the latent variable should be greater than the correlations of all other latent variables. The highlighted diagonal entries shown in Table 3 represent the results for discriminant validity. Similarly, Table 4 presents the result for the discriminant validity assessment using HTMT as recommended by Henseler, Ringle, \& Sarstedt [45]. The diagonal values in Table 4 indicate that all entries were below Clark and Watson [15]'s maximum requirement of 0.85. Moreover, Variance Inflation Factor (VIF) was used to evaluate the possibility of multicollinearity. All VIF values must be $<3$ [42]. Table 5 shows collinearity did not disturb the findings of the study. Finally, SRMR, NFI and RMS_theta was used to assess model fit. According to Henseler, Hubona, \& Ray [44], SRMR < 0.08, NFI greater than 0.90 and RMS_theta closer to zero is preferred. The results confirmed the validity of the model since all the tolerance level were met (see appendix two).

\subsection{Structural model}

The bootstrap technique was adopted to examine the significance and strength of the predicted relationships. Specifically, we examined the effect of Shared Language on Norm of Reciprocity, Social Interaction Ties and Identification and how these constructs also affected Trust. All predicted relationships were significant. In particular, Shared Language positively

\begin{tabular}{lllllllll}
\hline & CA & CR & AVE & ID & NR & SIT & SL & TR \\
\hline ID & 0.781 & 0.859 & 0.604 & 0.777 & & & & \\
NR & 0.754 & 0.858 & 0.670 & 0.695 & 0.818 & & & \\
SIT & 0.798 & 0.817 & 0.534 & 0.642 & 0.592 & 0.731 & & \\
SL & 0.786 & 0.827 & 0.615 & 0.728 & 0.671 & 0.579 & 0.784 & \\
TR & 0.787 & 0.863 & 0.613 & 0.586 & 0.578 & 0.653 & 0.513 & 0.783
\end{tabular}

Table 3.
Construct Validity and Reliability.

Note: CA; Cronbach's Alpha, CR; Composite Reliability, AVE; Average Variance Extracted.

Table 4.

Discriminant Validity Test with HeterotraitMonotrait Ratio (HTMT).

\begin{tabular}{lllll}
\hline & ID & NR & SIT & SL \\
\hline NR & 0.788 & & & \\
SIT & 0.772 & 0.788 & & \\
SL & 0.690 & 0.621 & 0.730 & 0.690 \\
TR & 0.740 & 0.729 & 0.774 & \\
\hline
\end{tabular}

\begin{tabular}{lrrrr}
\hline & ID & NR & SIT & TR \\
\hline ID & & & & 2.297 \\
NR & & & 1.820 & 2.082 \\
SIT & 1.504 & \multirow{2}{*}{1.000} & 1.820 & 1.828 \\
SL & 1.504 & & & \\
\hline
\end{tabular}


influenced Norm of Reciprocity $(\beta=0.671, \mathrm{p}<0.001)$, Social Interaction Ties $(\beta=0.330, \mathrm{p}<$ $0.001)$ and Identification $(\beta=0.537, \mathrm{p}<0.001)$ thus validating $\mathrm{H}_{1 \mathrm{a}}, \mathrm{H}_{1 \mathrm{~b}}$ and $\mathrm{H}_{1 \mathrm{c}}$.

Norm of Reciprocity $(\beta=0.371, \mathrm{p}<0.001)$ positively influenced Social Interaction Ties. Meanwhile, Social Interaction Ties $(\beta=0.331, \mathrm{p}<0.001)$ also positively affected Identification. From Figure 2 , it is also shown that Norm of Reciprocity $(\beta=0.211, p<$ $0.005)$, Social Interaction Ties $(\beta=0.419, \mathrm{p}<0.001)$ and Identification $(\beta=0.171, \mathrm{p}<0.01)$ all positively influenced Trust. This indicates that all the other five hypotheses $\left(\mathrm{H}_{2 \mathrm{a}}, \mathrm{H}_{2 \mathrm{~b}}, \mathrm{H}_{3 \mathrm{a}}, \mathrm{H}_{3 \mathrm{~b}}\right.$ and $\mathrm{H}_{4}$ ) were supported. Table 6 presents a summary of the significance of path coefficients. The effect sizes $\left(f^{2}\right)$ between constructs were also studied using Cohen [16]'s criteria. Cohen [16] asserted that the effect of a construct on the others can be irrelevant (i.e. $f^{2}<0.02$ ), small $(\geq 0.02)$, medium $(\geq 0.15)$ or large $(\geq 0.35)$. From Table 6 , Shared Language has a larger effect
Trust on social networking sites

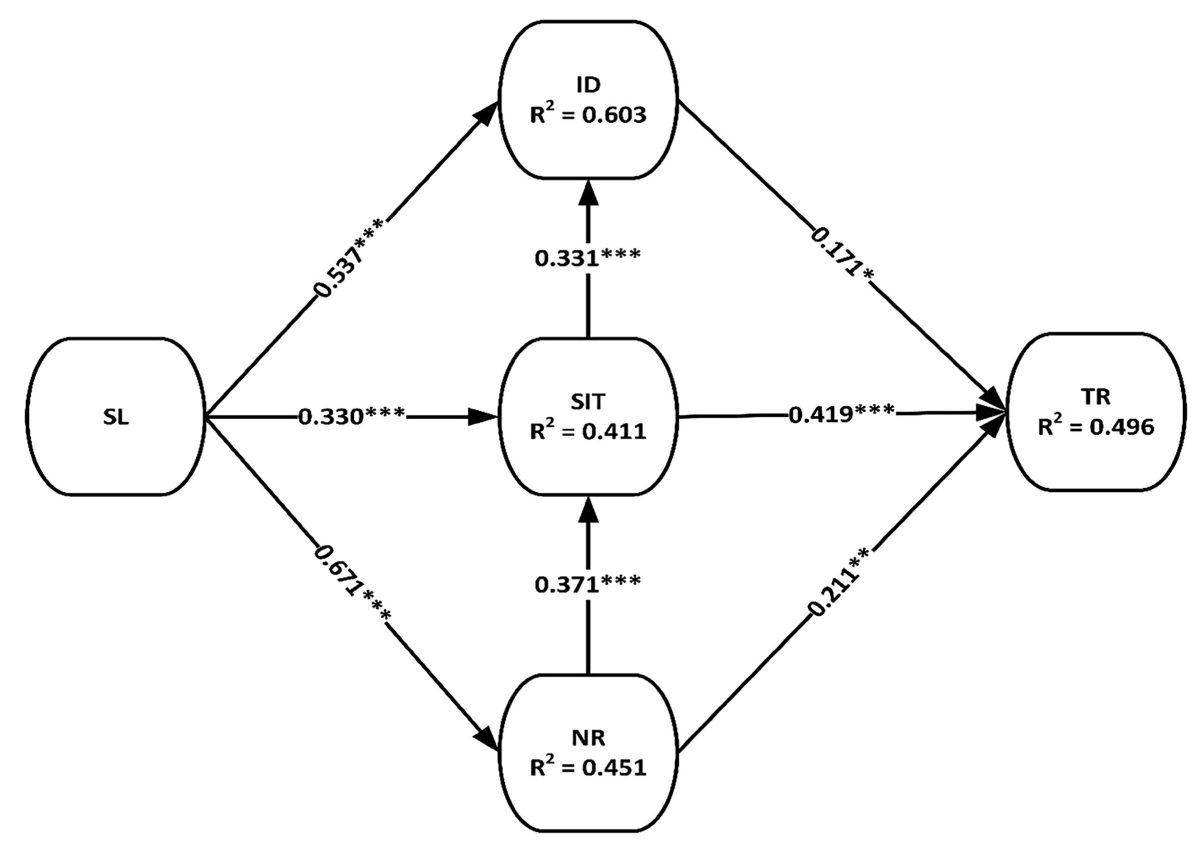

$* * * \mathrm{p}<0.001 ; * *_{\mathrm{p}}<0.005 ;{ }^{*} \mathrm{p}<0.01$

Figure 2.

PLS Analysis of Structural Model.

\begin{tabular}{|c|c|c|c|c|c|c|c|c|}
\hline & $\begin{array}{c}\text { Original } \\
\text { Sample }(O)\end{array}$ & $\begin{array}{c}\text { Sample } \\
\text { Mean (M) }\end{array}$ & $\begin{array}{l}\text { Standard } \\
\text { Deviation } \\
\text { (STDEV) }\end{array}$ & $\begin{array}{c}\text { T Statistics } \\
(|\mathrm{O} / \mathrm{STDEV}|)\end{array}$ & $\begin{array}{c}\mathrm{P} \\
\text { Values }\end{array}$ & $\begin{array}{l}\text { Effect } \\
\text { Size }\end{array}$ & Supported? & \\
\hline ID $->$ TR & 0.171 & 0.176 & 0.069 & 2.485 & 0.007 & 0.025 & Yes & \\
\hline NR $->$ SIT & 0.371 & 0.377 & 0.056 & 6.615 & 0.000 & 0.128 & Yes & \\
\hline NR -> TR & 0.211 & 0.210 & 0.074 & 2.845 & 0.002 & 0.042 & Yes & \\
\hline SIT $->$ ID & 0.331 & 0.330 & 0.046 & 7.239 & 0.000 & 0.183 & Yes & \\
\hline SIT $->$ TR & 0.419 & 0.418 & 0.057 & 7.303 & 0.000 & 0.190 & Yes & \\
\hline $\mathrm{SL}->\mathrm{ID}$ & 0.537 & 0.541 & 0.042 & 12.795 & 0.000 & 0.484 & Yes & Table 6. \\
\hline $\mathrm{SL}->\mathrm{NR}$ & 0.671 & 0.677 & 0.034 & 19.702 & 0.000 & 0.820 & Yes & Significance of Path \\
\hline SL $->$ SIT & 0.330 & 0.325 & 0.060 & 5.505 & 0.000 & 0.102 & Yes & Coefficients. \\
\hline
\end{tabular}


on norm of reciprocity (0.820) and Identification (0.484) but smaller effect on Social Interaction Ties (0.102). Similarly, while Identification (0.025) and Norm of Reciprocity (0.042) had small effects on Trust, Social Interaction Ties (0.190) had a medium effect.

The SmartPLS software was also used to assess the mechanisms through which all the independent variables affect the dependent variable using mediation analysis procedure. A partial mediation was observed among all the variables. This indicates that, the direct and indirect effects among all the variables were significant. This confirms Hämäläinen [43]'s position that, the constructs in the social capital theory significantly influence each other. Table 7 shows the summary of the mediation effects.

\section{Discussion}

Trust is one of the most important issues in online activities. However, relevant researches have predominantly focused on its consequences with little attention to its antecedents. Therefore, this study investigated the factors that promote Trust among SNS users. As stated earlier, the research model analyzed in this paper was tested with 921 Ghanaian university students who are users of various SNSs. In the next sections we discuss the theoretical and practical implications of our findings.

\subsection{Theoretical contribution}

The results of this study provide relevant theoretical contributions. Specifically, statistical tests on measurement model demonstrate acceptable convergent and discriminant validity whereas the structural model explained $49.6 \%$ of the variance in Trust among SNS users. This indicates that the proposed model is appropriate for examining the antecedents of Trust. In addition, it augments existing literature on SNS and Trust, especially when culture influences people's concept of Trust.

Previous studies had indicated that members of SNS platforms rarely interact [18,59] and thus making them lonely and depressed [83]. The results from this study refute such claims. Shared Language significantly affected Norm of Reciprocity, Social Interaction Ties and Identification. This suggests that, students with common perspectives are connected via SNS platforms. Therefore, this commonality enables seamless interactions among themselves thus permitting the formation of tighter bonds and also increases their participation in mutual exchanges. This outcome is consistent with findings from existing studies Aslam

Table 7.

Specific Indirect Effects.

\begin{tabular}{|c|c|c|c|c|c|}
\hline & $\begin{array}{c}\text { Original } \\
\text { Sample }(\mathrm{O})\end{array}$ & $\begin{array}{l}\text { Sample } \\
\text { Mean (M) }\end{array}$ & $\begin{array}{l}\text { Standard } \\
\text { Deviation } \\
\text { (STDEV) }\end{array}$ & $\begin{array}{l}\text { T Statistics } \\
(|\mathrm{O} / \mathrm{STDEV}|)\end{array}$ & $\begin{array}{c}\mathrm{P} \\
\text { Values }\end{array}$ \\
\hline NR $->$ SIT $->$ ID & 0.123 & 0.126 & 0.030 & 4.036 & 0.000 \\
\hline SL $->$ NR $->$ SIT $->$ ID & 0.082 & 0.085 & 0.021 & 3.913 & 0.000 \\
\hline SL $>$ SIT $>$ ID & 0.109 & 0.109 & 0.024 & 4.601 & 0.000 \\
\hline SL $->$ NR $->$ SIT & 0.249 & 0.253 & 0.043 & 5.836 & 0.000 \\
\hline NR $>>$ SIT $>$ ID $>$ TR & 0.021 & 0.022 & 0.011 & 1.933 & 0.027 \\
\hline SL $->$ NR $->$ SIT $->$ ID $->$ TR & 0.014 & 0.015 & 0.007 & 1.894 & 0.029 \\
\hline SIT -> ID -> TR & 0.057 & 0.058 & 0.026 & 2.213 & 0.014 \\
\hline $\mathrm{SL}->\mathrm{SIT}->\mathrm{ID}->\mathrm{TR}$ & 0.019 & 0.019 & 0.009 & 2.101 & 0.018 \\
\hline $\mathrm{SL}->\mathrm{ID}->\mathrm{TR}$ & 0.092 & 0.092 & 0.037 & 2.467 & 0.007 \\
\hline $\mathrm{SL}->\mathrm{NR}->\mathrm{TR}$ & 0.142 & 0.141 & 0.049 & 2.870 & 0.002 \\
\hline NR $>$ SIT $>>$ TR & 0.155 & 0.158 & 0.035 & 4.495 & 0.000 \\
\hline SL $->$ NR $>$ SIT $>>$ TR & 0.104 & 0.106 & 0.025 & 4.172 & 0.000 \\
\hline SL $->$ SIT $->$ TR & 0.138 & 0.138 & 0.033 & 4.191 & 0.000 \\
\hline
\end{tabular}


et al. [3,52,87]. For instance, many students on SNS prefer interactions on SNS and recognize the need to provide feedback [56] hence they easily identified with each other.

The results also indicated that Norm of Reciprocity, Social Interaction Ties and Identification were significant factors that promoted Trust. This means that, the integrity and honesty of colleagues are defined by their reciprocated responses. Students are more inclined to trust others who they expect to return support and favors. This finding is similar to previous studies conducted by Bouchillon [9] and Zhang, Li, Wu, \& Li, [92]. However it contradicts claims made by Bapna et al. [5]. Researches have shown that students spend a lot of time interacting with their friends on SNS platforms [67], Yeboah and Ewur [91]. Therefore, they are familiar with and purview to their principles and values. This increases their trust in colleagues and are able to identify with friends with similar beliefs and perceptions.

\subsection{Practical contributions}

The results from this study provide many insightful contributions for SNS developers who seek to promote Trust. First of all, SNS developers must design tools that augment shared interpretation on SNS. Specifically, they must develop algorithms that connect users with common beliefs. For instance, based on a person's profile and characteristics, the system could suggest others with similar characteristics to follow. This will enable people to easily find others with similar traits and values.

Also, in response to the significant impacts of social interactions and exchanges on SNS users' Trust, SNS developers must offer functionalities that support frequent communications and exchanges among users. Though most SNS offer synchronous peer to peer communications platforms such as Chats, it is imperative to introduce design features that persuade, encourage and motivate users to frequently interact with others via such media. Perhaps, reward systems and packages could be given to users who give prompt feedback to others.

Furthermore, designers should develop SNS systems that encourage the "We" feeling among SNS users. For example, the Twitter Feed feature increases the feeling of social presence. Such platforms are important enablers for users to witness the activities of their friends. Because, network members can easily relate to the activities of their friends, they get involve by liking or commenting. This increases members' perception of being part of a community and therefore develop strong attachment to their friends [11].

\section{Conclusion}

In an attempt to augment existing literature on SNS which had predominantly measured the effects of Trust, this study proposed a model to investigate the antecedents of Trust among SNS users. Particularly, it theorized that Shared Language predicted Norm of Reciprocity, Social Interaction Ties and Identification while these variables also predicted Trust. The analysis of data from 921 respondents using PLS-SEM validated these relationships. The study adopted the convenience sampling technique for data collection, though the random sampling approach would have been more suitable for this study. Hence, our findings cannot be generalized.

Further studies should be conducted in other jurisdictions to assess the applicability of the model in those settings. Also, the proposed relationships of the model were tested using crosssectional data. Given that peoples' ideologies and behavioral patterns changes with time, a longitudinal approach would have better explained the findings in the long term.

\section{References}

[1] K. Aillerie, S. McNicol, Are social networking sites information sources? Informational purposes of high-school students in using SNSs, J. Librarianship Inf. Sci. 50 (1) (2018) 103-114.
Trust on social networking sites 
[2] A.R. Ajiboye, M. Bakare, F. Usman-Hamza, S. Sulyman, The Impact of Social Network Sites on Knowledge and Information Sharing to Students in the Open Distance Learning Scheme, 2018.

[3] M.M.H. Aslam, K. Shahzad, A.R. Syed, A. Ramish, Social capital and knowledge sharing as determinants of academic performance, J. Behav. Appl. Manage. 15 (1) (2013) 25.

[4] R.P. Bagozzi, Y. Yi, On the evaluation of structural equation models, J. Acad. Mark. Sci. 16 (1) (1988) 74-94.

[5] R. Bapna, A. Gupta, S. Rice, A. Sundararajan, Trust and the strength of ties in online social networks: an exploratory field experiment, MIS Q. 41 (1) (2017) 115-130.

[6] D. Barclay, C. Higgins, R. Thompson, The Partial Least Squares (pls) Approach to Casual Modeling: Personal Computer Adoption Ans Use as an Illustration, 1995.

[7] A. Beldad, M. De Jong, M. Steehouder, How shall I trust the faceless and the intangible? A literature review on the antecedents of online trust, Comput. Hum. Behav. 26 (5) (2010) 857-869.

[8] M.C. Bolino, W.H. Turnley, J.M. Bloodgood, Citizenship behavior and the creation of social capital in organizations, Acad. Manage. Rev. 27 (4) (2002) 505-522.

[9] B.C. Bouchillon, Social ties and generalized trust, online and in person: contact or conflict: the mediating role of bonding social capital in America, Soc. Sci. Comput. Rev. 32 (4) (2014) 506-523.

[10] M. Brewer, R. Brown, Intergroup relations, The Handbook of Social Psychology, 1998.

[11] T. Chan, C. Cheung, N. Shi, M. Lee, Z. Lee, An empirical examination of continuance intention of social network sites, Pac. Asia J. Assoc. Inf. Syst. 8 (4) (2016) 5.

[12] H.H. Chang, S.-S. Chuang, Social capital and individual motivations on knowledge sharing: Participant involvement as a moderator, Inf. Manage. 48 (1) (2011) 9-18, http://dx.doi.org/10.1016/ J.IM.2010.11.001.

[13] Y. Chen, X. Yan, W. Fan, M. Gordon, The joint moderating role of trust propensity and gender on consumers' online shopping behavior, Comput. Hum. Behav. 43 (2015) 272-283.

[14] C.-M. Chiu, M.-H. Hsu, E.T.G. Wang, Understanding knowledge sharing in virtual communities: an integration of social capital and social cognitive theories, Decis. Support Syst. 42 (3) (2006) 1872-1888.

[15] L.A. Clark, D. Watson, Constructing validity: Basic issues in objective scale development, Psychol. Assess. 7 (3) (1995) 309.

[16] J. Cohen, Statistical Power Analysis for the Behavioral Sciences, second ed., erlbaum, Hillsdale, NJ, 1988.

[17] J.S. Coleman, Social capital in the creation of human capital. [Supplement, Organizations and institutions: Sociological and economic approaches to the analysis of social structure.], Am. J. Soc. 94 (1988) S95-S120.

[18] K. Collins, D. Shiffman, J. Rock, How are scientists using social media in the workplace?, PLoS ONE 11 (10) (2016) e0162680.

[19] T. Coltman, T.M. Devinney, D.F. Midgley, S. Venaik, Formative versus reflective measurement models: two applications of formative measurement, J. Bus. Res. 61 (12) (2008) 1250-1262.

[20] E. Constantinides, M.C. Zinck Stagno, Potential of the social media as instruments of higher education marketing: a segmentation study, J. Market. Higher Educ. 21 (1) (2011) 7-24, http://dx. doi.org/10.1080/08841241.2011.573593.

[21] K.S. Cook, C. Cheshire, E.R.W. Rice, S. Nakagawa, ). Social exchange theory, in: Handbook of Social Psychology, Springer, 2013, pp. 61-88.

[22] F.R. da Cunha Jr., C. van Kruistum, B. van Oers, Teachers and Facebook: using online groups to improve students communication and engagement in education, Commun. Teacher 30 (4) (2016) 228-241.

[23] K. David, C. Golan, The mediating effect of interpersonal trust on virtual team's collaboration, Int. J. Knowl. Manage. (IJKM) 13 (3) (2017) 20-37. 
[24] H. Donelan, Social media for professional development and networking opportunities in academia, J. Further Higher Educ. 40 (5) (2016) 706-729.

[25] R. Dubos, Social Capital: Theory and Research, Routledge, 2017.

[26] C.D. Dumitru, M.A. Schoop, How does trust in teams, team identification, and organisational identification impact trust in organisations?, Int J. Manage. Appl. Res. 3 (2) (2016) 87-97.

[27] N.B. Ellison, J. Vitak, R. Gray, C. Lampe, Cultivating social resources on social network sites: Facebook relationship maintenance behaviors and their role in social capital processes, J. Comput. -Mediated Commun. 19 (4) (2014) 855-870.

[28] T. Escobar-Rodr'liguez, R. Bonsón-Fernández, Analysing online purchase intention in Spain: fashion e-commerce, Inf. Syst. E-Bus. Manage. 15 (3) (2017) 599-622.

[29] M. Evans, A. Wensley, I. Frissen, The mediating effects of trustworthiness on social-cognitive factors and knowledge sharing in a large professional service firm, Electron. J. Knowl. Manage. 13 (3) (2015) 240-253, Retrieved from file: ///C:/CSCDATA/CSC/Raquel-2015/UOC/Gestióndeinform aciónparalainvestigación/20/ejkm-volume13-issue3-article685.pdf.

[30] J. Feng, J. Lazar, J. Preece, Empathy and online interpersonal trust: a fragile relationship, Behav. Inf. Technol. 23 (2) (2004) 97-106.

[31] C. Flavian, M. Guinaliu, P. Jordan, Antecedents and consequences of trust on a virtual team leader, Euro. J. Manage. Bus. Econ. 28 (1) (2019) 2-24.

[32] C. Fornell, D.F. Lacker, Evaluating structural equation modeling for travel behavior research, Transp. Res. Part B, Univ. Michigan 37 (1981) 1-25.

[33] F. Fukuyama, Trust: The Social Virtues and the Creation of Prosperity, Free Press Paperbacks, 1995.

[34] M. Ganzha, M. Paprzycki, I. Lirkov, Trust management in an agent-based grid resource brokering system-preliminary considerations, in: AIP Conference Proceedings, 2007, pp. 35-46.

[35] W. Gao, Z. Liu, J. Li, How does social presence influence SNS addiction? A belongingness theory perspective, Comput. Hum. Behav. 77 (2017) 347-355.

[36] D. Gefen, I. Benbasat, P. Pavlou, A research agenda for trust in online environments, J. Manage. Inf. Syst. 24 (4) (2008) 275-286.

[37] D. Gefen, E.E. Rigdon, D. Straub, Editor's comments: an update and extension to SEM guidelines for administrative and social science research, MIS Q. (2011) iii-xiv.

[38] A. Gokhale, K. Machina, Guided online group discussion enhances student critical thinking skills, Int. J. on E-Learn. 17 (2) (2018) 157-173.

[39] J.G.S. Goldie, Connectivism: a knowledge learning theory for the digital age?, Med Teach. 38 (10) (2016) 1064-1069.

[40] S. Grabner-Kräuter, S. Bitter, Trust in online social networks: a multifaceted perspective, in: Forum for social economics, 2015, pp. 48-68.

[41] J.F. Hair, M. Sarstedt, C.M. Ringle, J.A. Mena, An assessment of the use of partial least squares structural equation modeling in marketing research, J. Acad. Mark. Sci. 40 (3) (2012) 414-433.

[42] J.F. Hair Jr, G.T.M. Hult, C. Ringle, M. Sarstedt, A Primer on Partial Least Squares Structural Equation Modeling (PLS-SEM), Sage Publications, 2016.

[43] A. Hämäläinen, Trust Antecedents in Social Networking Services, 2015.

[44] J. Henseler, G. Hubona, P.A. Ray, Using PLS path modeling in new technology research: updated guidelines, Ind. Manage. Data Syst. 116 (1) (2016) 2-20.

[45] J. Henseler, C.M. Ringle, M. Sarstedt, A new criterion for assessing discriminant validity in variance-based structural equation modeling, J. Acad. Mark. Sci. 43 (1) (2015) 115-135.

[46] M.-H. Hsu, C.-M. Chang, C.-H. Yen, Exploring the antecedents of trust in virtual communities, Behav. Inf. Technol. 30 (5) (2011) 587-601. 
[47] I.R. Ismail, N. Tajuddin, N.K.M. Yunus, Trust and Intention to share as predictors of online knowledge-sharing behavior, in: Proceedings of the Regional Conference on Science, Technology and Social Sciences (RCSTSS 2016), 2019, pp. 57-67.

[48] W. Jeng, D. He, J. Jiang, User participation in an academic social networking service: A survey of open group users on Mendeley, J. Assoc. Inf. Sci. Technol. 66 (5) (2015) 890-904.

[49] W. Jeng, D. He, J. Jiang, Y. Zhang, in: Groups in Mendeley: Owners' Descriptions and Group Outcomes, Wiley Online Library, 2012, pp. 1-4.

[50] L.A. Joia, B. Lemos, Relevant factors for tacit knowledge transfer within organisations, J. Knowl. Manage. 14 (3) (2010) 410-427.

[51] A. Kavada, Creating the collective: social media, the Occupy Movement and its constitution as a collective actor, Inf., Commun. Soc. 18 (8) (2015) 872-886.

[52] F.N. Koranteng, I. Wiafe, Factors that promote knowledge sharing on academic social networking sites: an empirical study, Educ. Inf. Technol. 1-26 (2018), http://dx.doi.org/10.1007/s10639-0189825-0.

[53] F.N. Koranteng, I. Wiafe, E. Kuada, An empirical study of the relationship between social networking sites and students ' engagement in higher education, J. Educ. Comput. Res. (2018), http://dx.doi.org/10.1177/0735633118787528.

[54] J. Lim, J.C. Richardson, Exploring the effects of students' social networking experience on social presence and perceptions of using SNSs for educational purposes, Internet Higher Educ. 29 (2016) 31-39.

[55] G.A. Malatesh, K. Dhanasree, Purpose and Preference of Using Social Networking Sites by Adolescents. Scientists Joined As Life Member Of Society Of Krishi Vigyan, 2018, pp. 193.

[56] S. Marrs, S. Zumbrunn, C. McBride, J.K. Stringer, Exploring elementary student perceptions of writing Feedback, J. Educ. Psychol. 10 (1) (2016).

[57] D.H. Mcknight, M. Carter, J.B. Thatcher, P.F. Clay, Trust in a specific technology: An investigation of its components and measures, ACM Trans. Manage. Inf. Syst. (TMIS) 2 (2) (2011) 12.

[58] D.H. McKnight, V. Choudhury, C. Kacmar, The impact of initial consumer trust on intentions to transact with a web site: a trust building model, J. Strateg. Inf. Syst. 11 (3-4) (2002) 297-323.

[59] H. Meishar-Tal, E. Pieterse, Why do academics use academic social networking sites?, Int Rev. Res. Open Distrib. Learn. 18 (1) (2017).

[60] I.K. Mensah, E-government services adoption: the important elements of trust and transparency, Int J. Electron. Govern. Res. (IJEGR) 14 (3) (2018) 12-31.

[61] C. Moorman, R. Deshpande, G. Zaltman, Factors affecting trust in market research relationships, J. Market. 57 (1) (1993) 81-101.

[62] R.M. Morgan, S.D. Hunt, The commitment-trust theory of relationship marketing, J. Market. 58 (3) (1994) 20-38.

[63] J. Mu, G. Peng, E. Love, Interfirm networks, social capital, and knowledge flow, J. Knowl. Manage. 12 (4) (2008) 86-100.

[64] A. Mukherjee, P. Nath, Role of electronic trust in online retailing: A re-examination of the commitment-trust theory, Eur. J. Mark. 41 (9/10) (2007) 1173-1202.

[65] T. Oliveira, M. Alhinho, P. Rita, G. Dhillon, Modelling and testing consumer trust dimensions in ecommerce, Comput. Hum. Behav. 71 (2017) 153-164.

[66] F.O. Omotayo, S.O. Babalola, Factors influencing knowledge sharing among information and communication technology artisans in Nigeria, J. Syst. Inf. Technol. 18 (2) (2016) 148-169.

[67] M. Owusu-Acheaw, A.G. Larson, Use of social media and its impact on academic performance of tertiary institution students: a study of students of Koforidua Polytechnic, Ghana, J. Educ. Pract. 6 (6) (2015) 94-101. 
[68] S. Panahi, J. Watson, H. Partridge, Fostering interpersonal trust on social media: physicians' perspectives and experiences, Postgrad. Med. J. 92 (1084) (2016) 70-73.

[69] R.D. Putnam, Tuning in, tuning out: The strange disappearance of social capital in America, PS: Polit. Sci. Polit. 28 (4) (1995) 664-684.

[70] A. Quan-Haase, University Students' Local And Distant Social Ties: Using and integrating modes of communication on campus, Inf., Commun. Soc. 10 (5) (2007) 671-693, http://dx.doi.org/10.1080/ 13691180701658020.

[71] C.M. Ridings, D. Gefen, B. Arinze, Some antecedents and effects of trust in virtual communities, J. Strateg. Inf. Syst. 11 (3-4) (2002) 271-295.

[72] R. Roopchund, V. Ramesh, V. Jaunky, in: Use of Social Media for Improving Student Engagement at Université des Mascareignes (UDM, Springer, Singapore, 2019, pp. 11-20.

[73] J.B. Rotter, A new scale for the measurement of interpersonal trust, J. Pers. 35 (4) (1967) 651-665.

[74] R. Santa, J.B. MacDonald, M. Ferrer, The role of trust in e-Government effectiveness, operational effectiveness and user satisfaction: Lessons from Saudi Arabia in e-G2B, Govern. Inf. Q. (2018).

[75] B. Sarwar, S. Zulfiqar, S. Aziz, K. Ejaz Chandia, Usage of social media tools for collaborative learning: the effect on learning success with the moderating role of cyberbullying, J. Educ. Comput. Res. 57 (1) (2019) 246-279, http://dx.doi.org/10.1177/0735633117748415.

[76] F.D. Schoorman, R.C. Mayer, J.H. Davis, in: An integrative Model of Organizational Trust: Past, Present, and Future, Academy of Management Briarcliff Manor, NY, 2007, p. 10510.

[77] V. Shankar, G.L. Urban, F. Sultan, Online trust: a stakeholder perspective, concepts, implications, and future directions, J. Strateg. Inf. Syst. 11 (3-4) (2002) 325-344.

[78] E. Shiu, G. Walsh, L.M. Hassan, S. Parry, The direct and moderating influences of individual-level cultural values within web engagement: a multi-country analysis of a public information website, J. Bus. Res. 68 (3) (2015) 534-541.

[79] S.-C.J. Sin, K.-S. Kim, International students' everyday life information seeking: the informational value of social networking sites, Lib. Inf. Sci. Res. 35 (2) (2013) 107-116.

[80] Y.W. Sullivan, D.J. Kim, Assessing the effects of consumers' product evaluations and trust on repurchase intention in e-commerce environments, Int. J. Inf. Manage. 39 (2018) 199-219.

[81] H. Tajfel, J. Turner, The social identity theory of intergroup behaviour. u: Worchel S. i Austin WG (ur.) Psychology of intergroup relations, Chicago: Nelson Hall, 1986, pp. 7-24.

[82] H.H. Tan, D. Chee, Understanding interpersonal trust in a Confucian-influenced society: an exploratory study, Int. J. Cross Cult. Manage. 5 (2) (2005) 197-212.

[83] F. Tonioni, L. D’Alessandris, C. Lai, D. Martinelli, S. Corvino, M. Vasale, P. Bria, Internet addiction: hours spent online, behaviors and psychological symptoms, Gen. Hosp. Psychiatry 34 (1) (2012) 80-87.

[84] W. Tsai, S. Ghoshal, Social capital and value creation: the role of intrafirm networks, Acad. Manage. J. 41 (4) (1998) 464-476.

[85] S. Valenzuela, N. Park, K.F. Kee, Is there social capital in a social network site?: Facebook use and college students' life satisfaction, trust, and participation, J. Comput. -Mediated Commun. 14 (4) (2009) 875-901.

[86] V. Venkatesh, J.Y.L. Thong, F.K.Y. Chan, P.J.H. Hu, Managing citizens' uncertainty in egovernment services: the mediating and moderating roles of transparency and trust, Inf. Syst. Res. 27 (1) (2016) 87-111.

[87] Y. Wang, in: Antecedents of Social Network Trust in SNS Usage: The Moderating Role of Offline Familiarity, 2017, pp. 107-134, http://dx.doi.org/10.4236/sn.2017.62007.

[88] A.M. Warren, A. Sulaiman, N.I. Jaafar, Understanding civic engagement behaviour on Facebook from a social capital theory perspective, Behav. Inf. Technol. 34 (2) (2015) 163-175. 
[89] B.H. Wixom, H.J. Watson, An empirical investigation of the factors affecting data warehousing success, MIS Q. (2001) 17-41.

[90] J.-J. Wu, A.S.L. Tsang, Factors affecting members' trust belief and behaviour intention in virtual communities, Behav. Inf. Technol. 27 (2) (2008) 115-125.

[91] J. Yeboah, G.D. Ewur, The impact of WhatsApp messenger usage on students performance in Tertiary Institutions in Ghana, J. Educ. Pract. 5 (6) (2014) 157-164.

[92] C.-B. Zhang, Y.-N. Li, B. Wu, D.-J. Li, How WeChat can retain users: Roles of network externalities, social interaction ties, and perceived values in building continuance intention, Comput. Hum. Behav. 69 (2017) 284-293.

[93] L.G. Zucker, Production of trust: Institutional sources of economic structure, 1840-1920, Res. Organ. Behav. (1986).

\section{Appendix. One: Constructs, question items and loadings}

\begin{tabular}{|c|c|c|c|}
\hline \multirow[t]{3}{*}{ Shared Language } & SL1 & The members in my social network use common terms or jargons. & 0.848 \\
\hline & SL2 & $\begin{array}{l}\text { Members in my social network use understandable communication } \\
\text { pattern during the discussion. }\end{array}$ & \\
\hline & SL3 & Members in my social networks use understandable narrative forms. & 0.8 \\
\hline \multirow[t]{3}{*}{$\begin{array}{l}\text { Norm of } \\
\text { Reciprocity }\end{array}$} & NR1 & $\begin{array}{l}\text { I know that other members in my social network will help me, so it's } \\
\text { only fair to help other members. }\end{array}$ & 0.8 \\
\hline & NR2 & $\begin{array}{l}\text { I believe that members in my social network would support me if I need } \\
\text { it. }\end{array}$ & 88 \\
\hline & NR3 & $\begin{array}{l}\text { I share information with members in my social network as they always } \\
\text { do with me }\end{array}$ & 0.88 \\
\hline \multirow[t]{4}{*}{$\begin{array}{l}\text { Social Interaction } \\
\text { Ties }\end{array}$} & SIT1 & $\begin{array}{l}\text { I maintain close social relationships with some members in my social } \\
\text { network. }\end{array}$ & 08 \\
\hline & SIT2 & $\begin{array}{l}\text { I spend a lot of time interacting with some members in my social } \\
\text { network. }\end{array}$ & 0.85 \\
\hline & SIT3 & $\begin{array}{l}\text { I have frequent communication with some members in my social } \\
\text { network. }\end{array}$ & 0.94 \\
\hline & SIT4 & I establish contact with some members in my social network. & \\
\hline \multirow[t]{4}{*}{ Identification } & ID1 & I feel a sense of belonging towards my social network members. & \\
\hline & ID2 & $\begin{array}{l}\text { I have the feeling of togetherness or closeness in my social network } \\
\text { members. }\end{array}$ & \\
\hline & ID3 & I have a strong positive feeling toward my social network members. & \\
\hline & ID4 & I am proud to be a member of my social network members. & \\
\hline \multirow[t]{4}{*}{ Trust } & TR1 & $\begin{array}{l}\text { Members in my social network will not take advantage of others even } \\
\text { when the opportunity arises. }\end{array}$ & \\
\hline & TR2 & $\begin{array}{l}\text { Members in my social network will always keep the promises they } \\
\text { make to one another. }\end{array}$ & 0.8 \\
\hline & TR3 & $\begin{array}{l}\text { Members in my social network would not knowingly do anything to } \\
\text { disrupt the conversation. }\end{array}$ & 0.8 \\
\hline & TR4 & Members in my social network are truthful in dealing with one another. & \\
\hline
\end{tabular}


Appendix. Two: Model Fit Summary

Trust on social

networking

sites

Measure

Value

SRMR

NFI

0.940

RMS_theta

0.002

\section{Corresponding author}

Ferdinand Apietu Katsriku can be contacted at: fkatsriku@ug.edu.gh

For instructions on how to order reprints of this article, please visit our website:

www.emeraldgrouppublishing.com/licensing/reprints.htm

Or contact us for further details: permissions@emeraldinsight.com 